\title{
Study on the influence of the arrangement of battery pack on the steering characteristics of electric vehicles
}

\author{
Yang Liu*, Jianzhu Zhao**, Fachao Jiang*** \\ *College of Engineering, China Agricultural University, Beijing 100083, China, E-mail: 18810660225@163.com \\ **College of Engineering, China Agricultural University, Beijing 100083, China, E-mail: zhjzh@cau.edu.cn \\ ***College of Engineering, China Agricultural University, Beijing 100083, China, E-mail: jiangfachao@163.com \\ cross $^{\text {ref }}$ http://dx.doi.org/10.5755/j01.mech.22.6.13608
}

\section{Introduction}

With the development of automobile industry in China, people pay more attention to electric vehicles. The safe operation of the vehicle is related with the stability. The lateral stability of the electric vehicles is relevant with the steering characteristic. Though influenced by four tires' cornering stiffness and the suspension characteristics, the steering characteristic mainly depends on the longitudinal position of the center of gravity. The steering characteristic of electric vehicles has a great effect on steering control. The steering characteristic of electric vehicles has great influence on the ride comfort and the service life of the tire [1] as well. The study of steering characteristics mainly focused on the influence of the wheels [2-3], suspension structure [4], suspension system [5] and the control system and steering characteristics of four-wheel steering vehicles [6]. Because the battery pack is very heavy, the position of the battery pack directly influence the location of the center of gravity of the vehicle [7], and then affecting its steering characteristic greatly. Therefore, electric vehicles' steering characteristic depends on the position of battery pack so much.

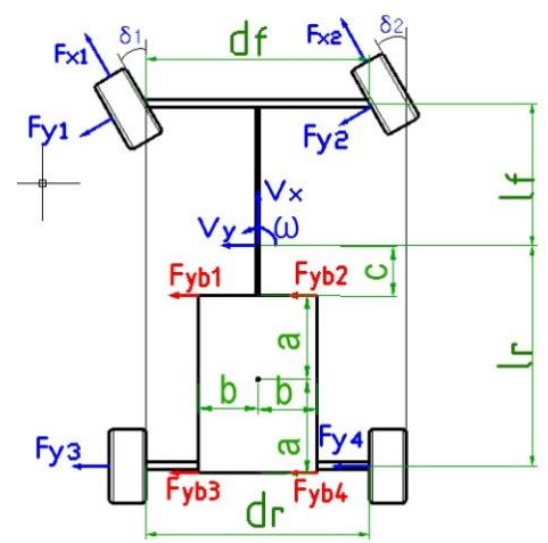

Fig. 1 Dynamics model-top view

\section{Vehicle dynamics model}

\subsection{Force and parameter definition}

The simulation is a main way to study the steering characteristic of vehicles, to begin with, establishing the dynamics model to meet the study requirements [8]. The top view is shown in Fig. 1. Isometric diagram is shown in Fig. 2. And isometric diagram of battery pack model is shown in Fig. 3.

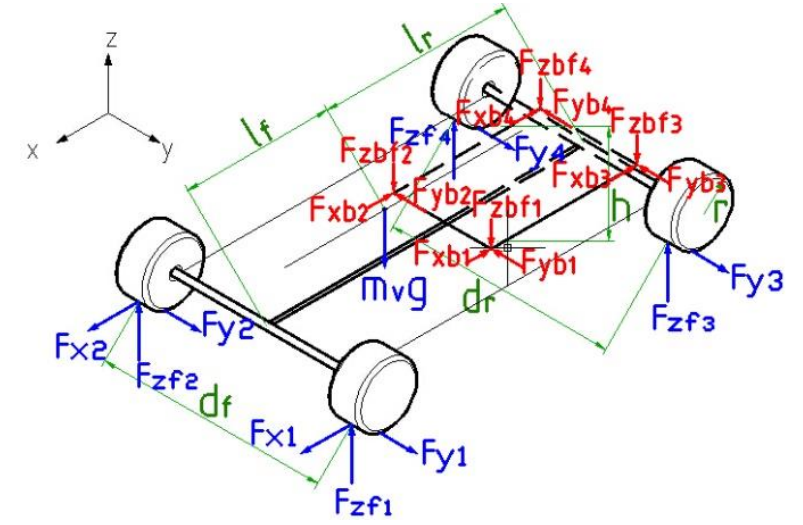

Fig. 2 Dynamics model (without battery pack)-isometric diagram

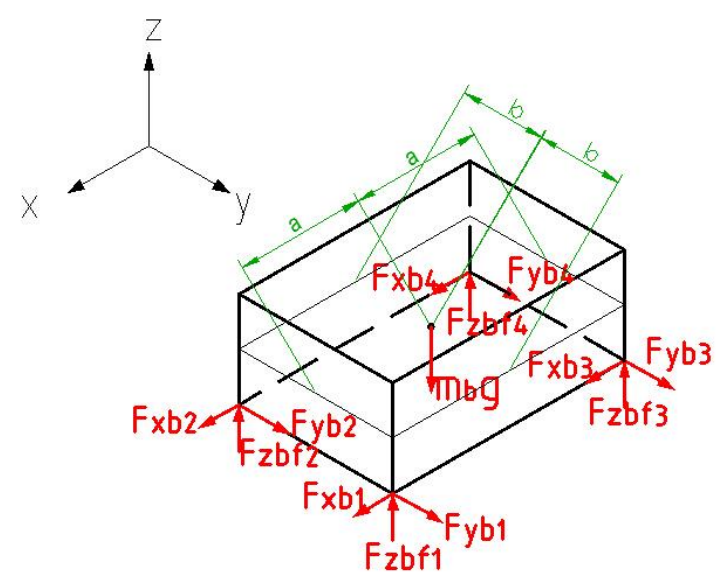

Fig. 3 Battery pack model-isometric diagram

2.2. Establish dynamics differential equation

According to D'Alembert principle, analyzing the forces of dynamics model, and then we can get the dynamics differential equation of the electric vehicle:

$$
\begin{aligned}
& m_{v}\left(\dot{v}_{x}-v_{y} \omega\right)=F_{x 1} \cos \delta_{1}+F_{x 2} \cos \delta_{2}-F_{y 1} \sin \delta_{1}- \\
& -F_{y 2} \sin \delta_{2}-F_{x b 1}-F_{x b 2}-F_{x b 3}-F_{x b 4} .
\end{aligned}
$$

The equation of lateral motion of the vehicle:

$$
\begin{aligned}
& m_{v}\left(\dot{v}_{y}-v_{x} \omega\right)=F_{y 3}+F_{y 4}+F_{x 1} \sin \delta_{1}+F_{x 2} \sin \delta_{2}+ \\
& +F_{y 1} \cos \delta_{1}+F_{y 2} \cos \delta_{2}-F_{y b 1}-F_{y b 2}-F_{y b 3}-F_{y b 4} .
\end{aligned}
$$


Table 1

Symbols in dynamics equation of the electric vehicle dynamics model

\begin{tabular}{|c|c|c|c|c|c|}
\hline Physical quantities & $\begin{array}{l}\text { Sym- } \\
\text { bol }\end{array}$ & Units & Physical quantities & $\begin{array}{l}\text { Sym- } \\
\text { bol }\end{array}$ & Units \\
\hline Longitudinal force of the left front wheel & $F_{x 1}$ & $\mathrm{~N}$ & Width of the battery pack & $2 b$ & $\mathrm{~m}$ \\
\hline Longitudinal force of the right front wheel & $F_{x 2}$ & $\mathrm{~N}$ & $\begin{array}{l}\text { Distance between the front edge of the bat } \\
\text { tery pack and the center of gravity }\end{array}$ & $c$ & $\mathrm{~m}$ \\
\hline Lateral force of the left front wheel & $F_{y 1}$ & $\mathrm{~N}$ & Mass of the battery pack & $m_{b}$ & $\mathrm{~kg}$ \\
\hline Lateral force of the right front wheel & $F_{y 2}$ & $\mathrm{~N}$ & $\begin{array}{l}\text { The battery pack's moment of inertia of } \\
\text { the } Z \text { axis }\end{array}$ & $I_{z b}$ & $\mathrm{~kg} \cdot \mathrm{m} 2$ \\
\hline Lateral force of the left rear wheel & $F_{y 3}$ & $\mathrm{~N}$ & $\begin{array}{l}\text { Longitudinal velocity component of the } \\
\text { left front wheel in the body coordinate }\end{array}$ & $v_{x 1}$ & $\mathrm{~m} / \mathrm{s}$ \\
\hline Lateral force of the right rear wheel & $F_{y 4}$ & $\mathrm{~N}$ & $\begin{array}{l}\text { Longitudinal velocity component of the } \\
\text { right front wheel in the body coordinate }\end{array}$ & $v_{x 2}$ & $\mathrm{~m} / \mathrm{s}$ \\
\hline Inside front-wheel side-slip angle & $\delta_{1}$ & $\mathrm{rad}$ & $\begin{array}{l}\text { Longitudinal velocity component of the } \\
\text { left rear wheel in the body coordinate }\end{array}$ & $v_{x 3}$ & $\mathrm{~m} / \mathrm{s}$ \\
\hline Outside front-wheel side-slip angle & $\delta_{2}$ & $\mathrm{rad}$ & $\begin{array}{l}\text { Longitudinal velocity component of the } \\
\text { right rear wheel in the body coordinate }\end{array}$ & $v_{x 4}$ & $\mathrm{~m} / \mathrm{s}$ \\
\hline $\begin{array}{l}\text { Distance between front axle and the center } \\
\text { of gravity }\end{array}$ & $l_{f}$ & & $\begin{array}{l}\text { Lateral velocity component of the left } \\
\text { front wheel in the body coordinate }\end{array}$ & $v_{y 1}$ & $\mathrm{~m} / \mathrm{s}$ \\
\hline $\begin{array}{l}\text { Distance between rear axle and the center } \\
\text { of gravity }\end{array}$ & $l_{r}$ & $\mathrm{~m}$ & $\begin{array}{l}\text { Lateral velocity component of the right } \\
\text { front wheel in the body coordinate }\end{array}$ & $v_{y 2}$ & $\mathrm{~m} / \mathrm{s}$ \\
\hline Vehicle speed & V & $\mathrm{m} / \mathrm{s}$ & $\begin{array}{l}\text { Lateral velocity component of the left rear } \\
\text { wheel in the body coordinate }\end{array}$ & $v_{y 3}$ & $\mathrm{~m} / \mathrm{s}$ \\
\hline Longitudinal speed & $v_{x}$ & $\mathrm{~m} / \mathrm{s}$ & $\begin{array}{l}\text { Lateral velocity component of the right } \\
\text { rear wheel in the body coordinate }\end{array}$ & $v_{y 4}$ & $\mathrm{~m} / \mathrm{s}$ \\
\hline Lateral speed & $v_{y}$ & $\mathrm{~m} / \mathrm{s}$ & The side slip angle of left front tire & $\alpha_{f 1}$ & $\mathrm{rad}$ \\
\hline Moment of inertia of the $\mathrm{Z}$ axis & $I_{z}$ & $\mathrm{~kg} \cdot \mathrm{m}^{2}$ & The side slip angle of right front tire & $\alpha_{f 2}$ & $\mathrm{rad}$ \\
\hline Front tread & $d_{f}$ & $\mathrm{~m}$ & The side slip angle of left rear tire & $\alpha_{f 3}$ & $\mathrm{rad}$ \\
\hline Rear tread & $d_{r}$ & $\mathrm{~m}$ & The side slip angle of right rear tire & $\alpha_{f 4}$ & $\mathrm{rad}$ \\
\hline $\begin{array}{l}\text { Longitudinal force } 1 \text { of the battery pack or } \\
\text { the frame(counterforce) }\end{array}$ & $F_{x b 1}$ & $\mathrm{~N}$ & Vertical load of left front wheel & $F_{z f 1}$ & $\mathrm{~N}$ \\
\hline $\begin{array}{l}\text { Longitudinal force } 2 \text { of the battery pack or } \\
\text { the frame(counterforce) }\end{array}$ & $F_{x b 2}$ & $\mathrm{~N}$ & Vertical load of right front wheel & $F_{z f 2}$ & $\mathrm{~N}$ \\
\hline $\begin{array}{l}\text { Longitudinal force } 3 \text { of the battery pack or } \\
\text { the frame(counterforce) }\end{array}$ & $F_{x b 3}$ & $\mathrm{~N}$ & Vertical load of left rear 0wheel & $F_{z f 3}$ & $\mathrm{~N}$ \\
\hline $\begin{array}{l}\text { Longitudinal force } 4 \text { of the battery pack or } \\
\text { the frame(counterforce) }\end{array}$ & $F_{x b 4}$ & $\mathrm{~N}$ & Vertical load of right rear wheel & $F_{z f 4}$ & $\mathrm{~N}$ \\
\hline $\begin{array}{l}\text { Lateral force } 1 \text { of the battery pack on the } \\
\text { frame(counterforce) }\end{array}$ & $F_{y b 1}$ & $\mathrm{~N}$ & Longitudinal acceleration of the vehicle & $a_{x}$ & $\mathrm{~m} / \mathrm{s} 2$ \\
\hline $\begin{array}{l}\text { Lateral force } 2 \text { of the battery pack on the } \\
\text { frame(counterforce) }\end{array}$ & $F_{y b 2}$ & $\mathrm{~N}$ & Lateral acceleration of the vehicle & $a_{y}$ & $\mathrm{~m} / \mathrm{s} 2$ \\
\hline $\begin{array}{l}\text { Lateral force } 3 \text { of the battery pack on the } \\
\text { frame(counterforce) }\end{array}$ & $F_{y b 3}$ & $\mathrm{~N}$ & $\begin{array}{l}\text { Distance between the center of gravity and } \\
\text { ground }\end{array}$ & $h$ & $\mathrm{~m}$ \\
\hline $\begin{array}{l}\text { Lateral force } 4 \text { of the battery pack on the } \\
\text { frame(counterforce) }\end{array}$ & $F_{y b 4}$ & $\mathrm{~N}$ & Cornering stiffness of left front wheel & $k_{1}$ & $\mathrm{~N} / \mathrm{rad}$ \\
\hline $\begin{array}{l}\text { Normal force } 1 \text { of the battery pack on the } \\
\text { frame(counterforce) }\end{array}$ & $F_{z b 1}$ & $\mathrm{~N}$ & Cornering stiffness of right front wheel & $k_{2}$ & $\mathrm{~N} / \mathrm{rad}$ \\
\hline $\begin{array}{l}\text { Normal force } 2 \text { of the battery pack on the } \\
\text { frame(counterforce) }\end{array}$ & $F_{z b 2}$ & $\mathrm{~N}$ & Cornering stiffness of left rear wheel & $k_{3}$ & $\mathrm{~N} / \mathrm{rad}$ \\
\hline $\begin{array}{l}\text { Normal force } 3 \text { of the battery pack on the } \\
\text { frame(counterforce) }\end{array}$ & $F_{z b 3}$ & $\mathrm{~N}$ & Cornering stiffness of right rear wheel & $k_{4}$ & $\mathrm{~N} / \mathrm{rad}$ \\
\hline $\begin{array}{l}\text { Normal force } 4 \text { of the battery pack on the } \\
\text { frame(counterforce) }\end{array}$ & $F_{z b 4}$ & $\mathrm{~N}$ & Radius of wheel & $r$ & $\mathrm{~m}$ \\
\hline Mass (without battery pack) & $m_{v}$ & $\mathrm{~kg}$ & Engine torque & $T_{t q}$ & $\mathrm{~N} \cdot \mathrm{m}$ \\
\hline Yaw rate & $\omega$ & $\mathrm{rad} / \mathrm{s}$ & Transmission ratio & $i_{g}$ & \\
\hline Sideslip angle & $\beta$ & $\mathrm{rad}$ & Main reducing gear ratio & $i_{0}$ & \\
\hline Length of the battery pack & $2 a$ & $\mathrm{~m}$ & Transmission efficiency & $\eta_{T}$ & \\
\hline
\end{tabular}


The equation of yaw motion of the vehicle:

$$
\begin{aligned}
I_{Z} \dot{\omega} & =1_{f}\left(F_{y 1} \cos \delta_{1}+F_{y 1} \cos \delta_{2}+F_{x 1} \sin \delta_{1}+F_{x 2} \sin \delta_{2}\right)+\frac{d_{f}}{2}\left(-F_{x 1} \cos \delta_{1}+F_{y 1} \sin \delta_{1}+F_{x 2} \cos \delta_{2}-F_{y 2} \sin \delta_{2}\right)- \\
& -l_{r}\left(F_{y 3}+F_{y 4}\right)+\left(F_{x b 1}+F_{x b 3}-F_{x b 2}-F_{x b 4}\right) b+\left(F_{y b 1}+F_{y b 2}\right) c+\left(F_{y b 3}+F_{y b 4}\right)(c+2 a) .
\end{aligned}
$$

The equation of longitudinal motion of the battery pack:

$$
m_{b}\left(\dot{v}_{x}-v_{y} \omega\right)=F_{x b 1}+F_{x b 2}+F_{x b 3}+F_{x b 4} .
$$

The equation of lateral motion of the battery pack:

$$
m_{b}\left(\dot{v}_{y}+v_{x} \omega\right)=F_{y b 1}+F_{y b 2}+F_{y b 3}+F_{y b 4} .
$$

$$
v_{x 4}=v_{x}+\frac{d_{r}}{2} \omega ; v_{y 4}=v_{y}-l_{r} \omega .
$$

The equation of yaw motion of the battery pack:

$$
\begin{aligned}
I_{z b} \dot{\omega}= & a\left(F_{y b 1}+F_{y b 2}-F_{y b 3}-F_{y b 4}\right)+ \\
& +b\left(F_{x b 2}-F_{x b 1}+F_{x b 4}-F_{x b 3}\right) .
\end{aligned}
$$

Resolving the speed in the direction parallel to the body coordinate system, and then we can get:

$$
\begin{aligned}
& v_{x 1}=v_{x}-\frac{d_{f}}{2} \omega ; v_{y 1}=v_{y}+l_{f} \omega ; \\
& v_{x 2}=v_{x}+\frac{d_{f}}{2} \omega ; v_{y 2}=v_{y}+l_{f} \omega ; \\
& v_{x 3}=v_{x}-\frac{d_{r}}{2} \omega ; v_{y 3}=v_{y}-l_{r} \omega ;
\end{aligned}
$$

The side slip angle of each tire:

$$
\alpha_{f 1}=\tan ^{-1}\left(\frac{v_{y 1}}{v_{x 1}}\right)-\delta_{1}=\tan ^{-1}\left(\frac{v_{y}+l_{f} \omega}{v_{x}-\frac{d_{f}}{2} \omega}\right)-\delta_{1} ;
$$

$$
\alpha_{f 2}=\tan ^{-1}\left(\frac{v_{y 2}}{v_{x 2}}\right)-\delta_{2}=\tan ^{-1}\left(\frac{v_{y}+l_{f} \omega}{v_{x}+\frac{d_{f}}{2} \omega}\right)-\delta_{2} ;
$$

$$
\alpha_{f 3}=\tan ^{-1}\left(\frac{v_{y 3}}{v_{x 3}}\right)=\tan ^{-1}\left(\frac{v_{y}-l_{r} \omega}{v_{x}-\frac{d_{r}}{2} \omega}\right) ;
$$

$$
\alpha_{f 4}=\tan ^{-1}\left(\frac{v_{y 4}}{v_{x 4}}\right)=\tan ^{-1}\left(\frac{v_{y}-l_{r} \omega}{v_{x}+\frac{d_{r}}{2} \omega}\right) .
$$

Considering the lateral load transfer and longitudinal acceleration, we can get vertical load of each wheel:

$$
\begin{gathered}
F_{z f 1}=\frac{l_{r}}{2\left(l_{f}+l_{r}\right)} m_{v} g-\frac{h}{2\left(l_{f}+l_{r}\right)} m_{v} a_{x}-\frac{h l_{r}}{d\left(l_{f}+l_{r}\right)} m_{v} a_{y} ; \\
F_{z f 2}=\frac{l_{r}}{2\left(l_{f}+l_{r}\right)} m_{v} g-\frac{h}{2\left(l_{f}+l_{r}\right)} m_{v} a_{x}+\frac{h l_{r}}{d\left(l_{f}+l_{r}\right)} m_{v} a_{y} ; \\
F_{z f 3}=\frac{l_{f}}{2\left(l_{f}+l_{r}\right)} m_{v} g+\frac{h}{2\left(l_{f}+l_{r}\right)} m_{v} a_{x}-\frac{h l_{f}}{d\left(l_{f}+l_{r}\right)} m_{v} a_{y} ; \\
F_{z f 4}=\frac{l_{f}}{2\left(l_{f}+l_{r}\right)} m_{v} g+\frac{h}{2\left(l_{f}+l_{r}\right)} m_{v} a_{x}+\frac{h l_{f}}{d\left(l_{f}+l_{r}\right)} m_{v} a_{y} .
\end{gathered}
$$

Ground reaction force to each wheel:

$$
\begin{aligned}
& F_{y 1}=k_{1} \alpha_{f 1} ; \\
& F_{y 2}=k_{2} \alpha_{f 2} ; \\
& F_{y 3}=k_{3} \alpha_{f 3} ; \\
& F_{y 4}=k_{4} \alpha_{f 4} .
\end{aligned}
$$

The expression of side slip angle $\beta$ of the electric vehicle is $\tan ^{-1} \frac{v_{y}}{v_{x}}$, normally, $\left|v_{x}\right|>>\left|v_{y}\right|$, so $|\beta|<<1$, when the vehicle drive uniformly, $v=\sqrt{v_{x}^{2}+v_{y}^{2}}=$ constant , then:

$$
\begin{aligned}
& v_{x}=v \cos \beta \approx v ; v_{y}=v \sin \beta \approx v \beta ; \\
& \dot{v}_{x}=-v \sin \beta \dot{\beta} \approx-v \beta \dot{\beta} ; \dot{v}_{y}=v \cos \beta \dot{\beta} \approx v \dot{\beta} .
\end{aligned}
$$

So along $\mathrm{X}$ and $\mathrm{Y}$ axis, accelerations of the electric vehicle are: 


$$
\begin{aligned}
& a_{x}=\left(\dot{v}_{x}-v_{y} \omega\right)=(-v \beta \dot{\beta}-v \beta \omega)=-v \beta(\dot{\beta}+\omega) ; \\
& a_{y}=\left(\dot{v}_{y}+v_{x} \omega\right)=(v \dot{\beta}+v \omega)=v(\dot{\beta}+\omega) .
\end{aligned}
$$

Because the side slip angle $\beta$ is very small, we can consider the center of mass acceleration is perpendicular to the direction of the speed, about $v(\dot{\beta}+\omega)$. Because $\beta$ is very small, the vehicle's speed and the longitudinal $\mathrm{X}$ axis direction are basically identical. At the same time, the acceleration and lateral Y axis direction are basically identi cal too.

Lateral speed produce the side slip angle in the location of the center of gravity, and then yaw movement produce side slip angle on the wheel too. The longitudinal velocity of each wheel is much larger than lateral velocity, what's more, because of $\left|\frac{l_{f}}{v}\right|\left|\frac{l_{r}}{v}\right|\left|\frac{d_{f} \omega}{2 v}\right|\left|\frac{d_{r} \omega}{2 v}\right|<<1$, the above formulas can be simplified and we can get the side slip of each wheel:

$$
\begin{aligned}
& \alpha_{f 1}=\tan ^{-1}\left(\frac{v_{y 1}}{v_{x 1}}\right)-\delta_{1}=\tan ^{-1}\left(\frac{v_{y}+l_{f} \omega}{v_{x}-\frac{d_{f}}{2} \omega}\right)-\delta_{1}=\frac{v \beta+l_{f} \omega}{v-\frac{d_{f}}{2} \omega}-\delta_{1} \approx \beta+\frac{l_{f} \omega}{v}-\delta_{1} ; \\
& \alpha_{f 2}=\tan ^{-1}\left(\frac{v_{y 2}}{v_{x 2}}\right)-\delta_{2}=\tan ^{-1}\left(\frac{v_{y}+l_{f} \omega}{v_{x}+\frac{d_{f}}{2} \omega}\right)-\delta_{2}=\frac{v \beta+l_{f} \omega}{v+\frac{d_{f}}{2} \omega}-\delta_{2} \approx \beta+\frac{l_{f} \omega}{v}-\delta_{2} ; \\
& \alpha_{f 3}=\tan ^{-1}\left(\frac{v_{y 3}}{v_{x 3}}\right)=\tan ^{-1}\left(\frac{v_{y}-l_{r} \omega}{v_{x}-\frac{d_{f}}{2} \omega}\right)=\frac{v \beta-l_{r} \omega}{v-\frac{d_{f}}{2} \omega} \approx \beta-\frac{l_{r} \omega}{v} ; \\
& \alpha_{f 4}=\tan ^{-1}\left(\frac{v_{y 4}}{v_{x 4}}\right)=\tan ^{-1}\left(\frac{v_{y}-l_{r} \omega}{v_{x}+\frac{d_{r}}{2} \omega}\right)=\frac{v \beta-l_{r} \omega}{v+\frac{d_{r}}{2} \omega} \approx \beta-\frac{\operatorname{lr} \omega}{v} .
\end{aligned}
$$

The longitudinal forces can be gotten by two front wheels:

$$
\begin{aligned}
& F_{x 1}=F_{x 2}=\frac{T_{t q} i_{g} i_{0} \eta_{T}}{2 r} . \\
& -m_{v} v \beta(\dot{\beta}+\omega)=-\left(k_{1} \delta_{1}+k_{2} \delta_{2}\right) \beta-\left(k_{1} \delta_{1} \frac{l_{f}}{v}+k_{2} \delta_{2} \frac{l_{f}}{v}\right) \omega+\frac{T_{t q} i_{g} i_{0} \eta_{T}}{r}+k_{1} \delta_{1}^{2}+k_{2} \delta_{2}^{2}-F_{x b 1}-F_{x b 2}-F_{x b 3}-F_{x b 4} .
\end{aligned}
$$

The equation of lateral motion of the vehicle:

$$
\begin{aligned}
m_{v} v(\dot{\beta}+\omega)= & \left(k_{1}+k_{2}+k_{3}+k_{4}\right) \beta+\left(k_{1} \frac{l_{f}}{v}+k_{2} \frac{l_{f}}{v}-k_{3} \frac{l_{\mathrm{r}}}{v}-k_{4} \frac{l_{r}}{v}\right) \omega+ \\
& +\frac{T_{t q} i_{g} i_{0} \eta_{T}}{2 \mathrm{r}} \delta_{1}+\frac{T_{t q} i_{g} i_{0} \eta_{T}}{2 \mathrm{r}} \delta_{2}-k_{1} \delta_{1}-k_{2} \delta_{2}-F_{\mathrm{y} b 1}-F_{y b 2}-F_{y b 3}-F_{y x b 4} .
\end{aligned}
$$

The equation of yaw motion of the vehicle:

$$
\begin{aligned}
& {\left[l_{f}\left(k_{1}+k_{2}\right)+\frac{d_{f}}{2}\left(k_{1} \delta_{1}-k_{2} \delta_{2}\right)-l_{r}\left(k_{3}+k_{4}\right)\right] \beta+\frac{2\left(k_{1}+k_{2}\right) l_{f}^{2}+2\left(k_{3}+k_{4}\right) l_{r}^{2}+\left(k_{1} \delta_{1}-k_{2} \delta_{2}\right) l_{f} d_{f}}{2 v} \omega-} \\
& -l_{f}\left(k_{1} \delta_{1}+k_{2} \delta_{2}-\frac{T_{t q} i_{g} i_{0} \eta_{T}}{2 r} \delta_{1}-\frac{T_{t q} i_{g} i_{0} \eta_{T}}{2 r} \delta_{2}\right)-\frac{d_{f}}{2}\left(\frac{T_{t q} i_{g} i_{0} \eta_{T}}{2 r}+k_{1} \delta_{1}^{2}-\frac{T_{t q} i_{g} i_{0} \eta_{T}}{2 r}-k_{2} \delta_{2}^{2}\right)+ \\
& +\left(F_{x b 1}+F_{x b 3}-F_{x b 2}-F_{x b 4}\right) b+\left(F_{y b 1}+F_{y b 2}\right) c+\left(F_{y b 3}+F_{y b 4}\right)(c+2 a)=I_{z} \dot{\omega} .
\end{aligned}
$$




\section{Simulation}

Matlab/Simulink used to solve mathematical model, as shown below [9].

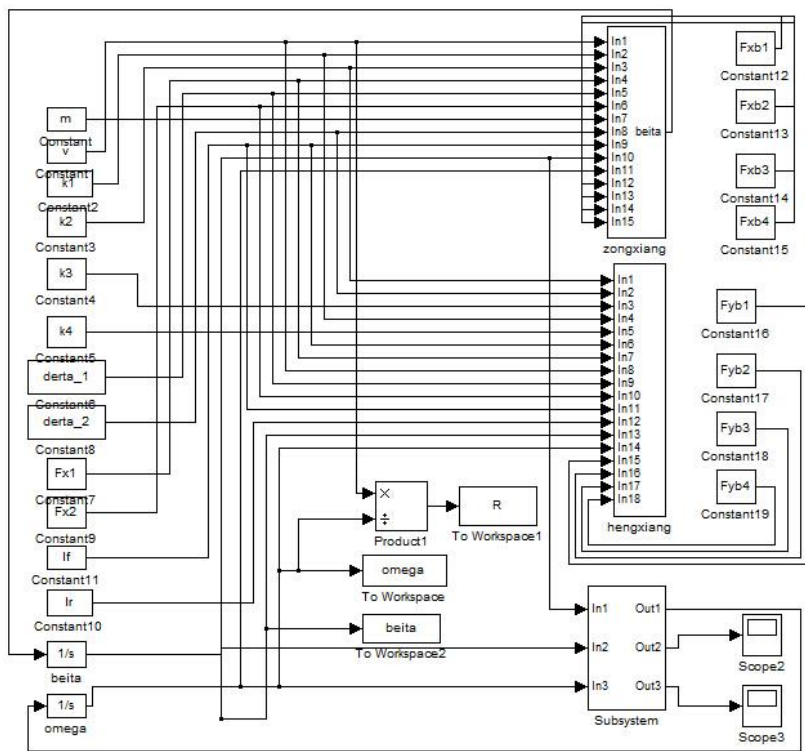

Fig. 4 Simulation model of steering characteristic of the electric vehicle

The parameters of the electric vehicle

Table 2

\begin{tabular}{|l|c|}
\hline \multicolumn{1}{|c|}{ Name } & Parameter \\
\hline Electric vehicle's length*width*height, mm & $\begin{array}{c}4550 * 1700^{*} \\
1660\end{array}$ \\
\hline $\begin{array}{l}\text { The whole mass (except the battery pack) } \\
m_{v}, \mathrm{~kg}\end{array}$ & 1800 \\
\hline The mass of battery pack $m_{b}, \mathrm{~kg}$ & 300 \\
\hline Battery pack's length*width*height, mm & $\begin{array}{c}890^{*} 600 * \\
360\end{array}$ \\
\hline Front tread $d_{f}, \mathrm{~mm}$ & 1414 \\
\hline Rear tread $d_{r}, \mathrm{~mm}$ & 1422 \\
\hline Radius of wheel $r$, mm & 367 \\
\hline $\begin{array}{l}\text { Distance between front axle and the center of } \\
\text { gravity } l_{f}, \mathrm{~mm}\end{array}$ & 1154 \\
\hline $\begin{array}{l}\text { Distance between rear axle and the center of } \\
\text { gravity } l_{r}, \text { mm }\end{array}$ & 1394 \\
\hline Moment of inertia of the Z axis $I_{Z}, \mathrm{~kg} \cdot \mathrm{m}^{2}$ & 5000 \\
\hline Moment of inertia of the Y axis $I_{Y}, \mathrm{~kg} \cdot \mathrm{m}^{2}$ & 867 \\
\hline Moment of inertia of the Z axis $I_{X}, \mathrm{~kg} \cdot \mathrm{m}^{2}$ & 6210 \\
\hline $\begin{array}{l}\text { Cornering stiffness of left front wheel } k_{1}, \\
\text { N/rad }\end{array}$ & -50000 \\
\hline $\begin{array}{l}\text { Cornering stiffness of right front wheel } k_{2}, \\
\text { N/rad }\end{array}$ & -50000 \\
\hline $\begin{array}{l}\text { Cornering stiffness of left rear wheel } k_{3}, \\
\text { N/rad }\end{array}$ & -50000 \\
\hline $\begin{array}{l}\text { Cornering stiffness of right rear wheel } k_{4}, \\
\text { N/rad }\end{array}$ & -50000 \\
\hline
\end{tabular}

\subsection{Steering transient response of the electric vehicle}

The front wheel angle step input test: while the vehicle is driving straight with steady-state, turning the steering wheel sharply to a corner, then stop turning the steering wheel and keep the angle of the same, after that the vehicle is driving along the uniform circular road. This test can reflect the transient response characteristics and steady state response characteristics, and we can observe changes of the yaw rate and the side slip angle in the whole process.

Setting the velocity of the electric vehicle is $15 \mathrm{~m} / \mathrm{s}$ ,inner steered angle $\delta_{1}=19.47^{\circ}$, the vehicle begin to turn from the start, and then we can get graphs of the yaw rate and the side slip angle ,as shown in Figs. 5 and 6 .

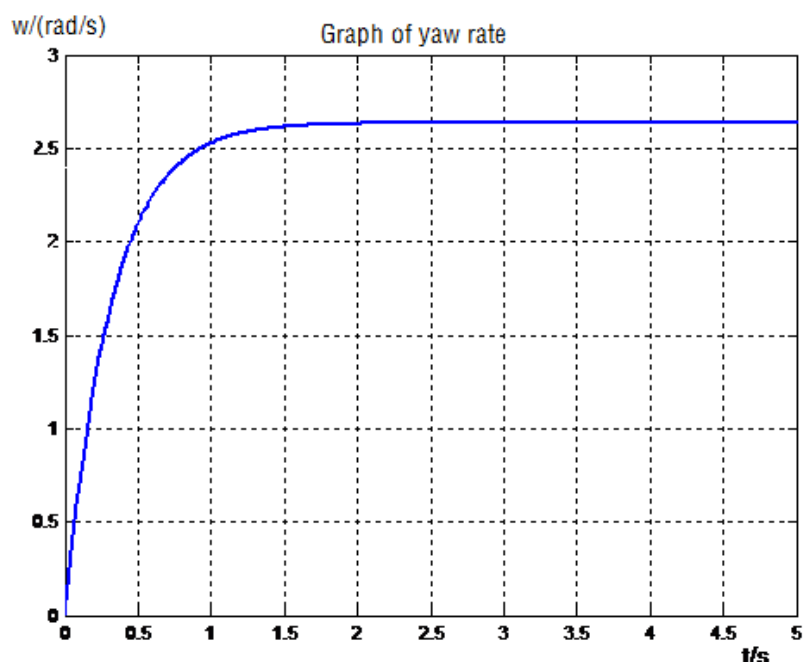

Fig. 5 Graph of yaw rate

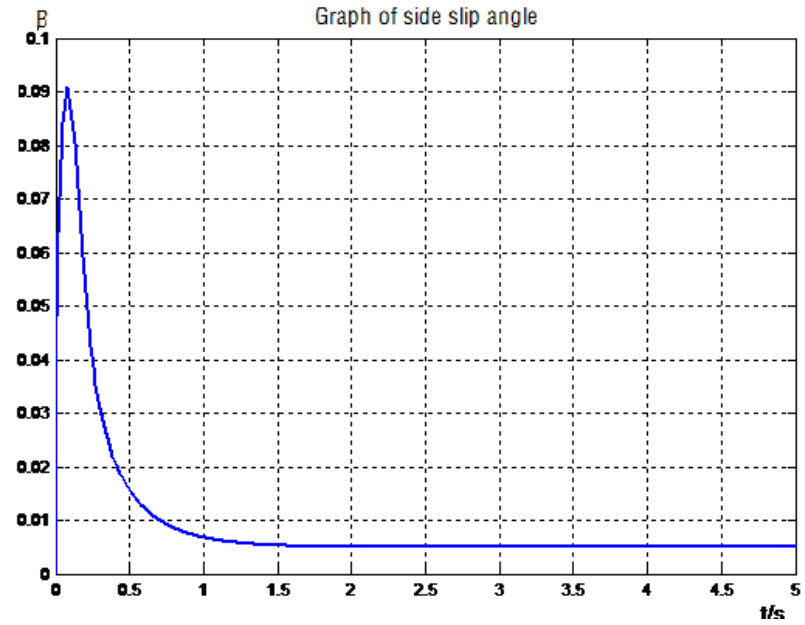

Fig. 6 Graph of side slip angle

\subsection{The steady-state response of the electric vehicle}

3-DOF model was used to study the motion of the electric vehicle. When the electric vehicle is driving with constant velocity, we analyzed the steady state response under the front-wheel-step input. The vehicle drives along the $9 \mathrm{~m}$-radius of circle with the lowest stable speed. And inside and outside front wheel angle are $\delta_{1}, \delta_{2}$ respectively. Because of the low speed, the centrifugal force is small, and the tire side-slip angle can be neglected, then the turning radius $R_{0}=u_{0} / \omega_{0}$. Keep the front wheel angles $\left(\delta_{1}, \delta_{2}\right)$ constant, and make the vehicle speed slowly and continuously (the longitudinal acceleration is less than $0.25 \mathrm{~m} / \mathrm{s}^{2}$ ), until the vehicle lateral acceleration up to $6.5 \mathrm{~m} / \mathrm{s}^{2}$. Measuring speed $(u)$ and yaw rate $(\omega)$ continuously, according to the formula $R=u / \omega$, we can get turning radius with side-slip angle, $R / R_{0}-V$ can represent steering characteristics of the vehicle. 
When the vehicle is driving with uniform circular motion, the side slip angle and yaw rate are constant, it means $\dot{\beta}=0, \dot{\omega}=0$, then we can get the steady-state differential equations of the electric vehicle.

The equation of longitudinal motion of the vehicle:

$$
-m_{v} v \beta \omega=-\left(k_{1} \delta_{1}+k_{2} \delta_{2}\right) \beta-\left(k_{1} \delta_{1} \frac{l_{f}}{v}+k_{2} \delta_{2} \frac{l_{f}}{v}\right) \omega+\frac{T_{\mathrm{d} 1}-I_{\omega} \dot{\omega}_{f 1}}{\mathrm{r}}+\frac{T_{\mathrm{d} 2}-I_{\omega} \dot{\omega}_{f 2}}{\mathrm{r}}+k_{1} \delta_{1}^{2}+k_{2} \delta_{2}^{2} .
$$

The equation of lateral motion of the vehicle:

$$
\begin{aligned}
m_{v} v \omega= & \left(k_{1}+k_{2}+k_{3}+k_{4}\right) \beta+\left(k_{1} \frac{l_{f}}{v}+k_{2} \frac{l_{f}}{v}-k_{3} \frac{l_{\mathrm{r}}}{v}-k_{4} \frac{l_{r}}{v}\right) \omega+\frac{T_{\mathrm{d} 1}-I_{\omega} \dot{\omega}_{f 1}}{\mathrm{r}} \delta_{1}+\frac{T_{\mathrm{d} 2}-I_{\omega} \dot{\omega}_{f 2}}{\mathrm{r}} \delta_{2}- \\
& -k_{1} \delta_{1}-k_{2} \delta_{2}-F_{\mathrm{y} b 1}-F_{y b 2}-F_{y b 3}-F_{y x b 4} .
\end{aligned}
$$

The equation of yaw motion of the vehicle:

$$
\begin{aligned}
& {\left[l_{f}\left(k_{1}+k_{2}\right)+\frac{d_{f}}{2}\left(k_{1} \delta_{1}-k_{2} \delta_{2}\right)-l_{r}\left(k_{3}+k_{4}\right)\right] \beta+\frac{2\left(k_{1}+k_{2}\right) l_{f}^{2}+2\left(k_{3}+k_{4}\right) l_{r}^{2}+\left(k_{1} \delta_{1}-k_{2} \delta_{2}\right) l_{f} d_{f}}{2 v} \omega-} \\
& -l_{f}\left(k_{1} \delta_{1}+k_{2} \delta_{2}-\frac{T_{d 1}-I_{\omega} \dot{\omega}_{f 1}}{r} \delta_{1}-\frac{T_{d 2}-I_{\omega} \dot{\omega}_{f 2}}{r} \delta_{2}\right)-\frac{d_{f}}{2}\left(\frac{T_{d 1}-I_{\omega} \dot{\omega}_{f 1}}{r}+k_{1} \delta_{1}^{2}-\frac{T_{d 2}-I_{\omega} \dot{\omega}_{f 2}}{r}-k_{2} \delta_{2}^{2}\right)+ \\
& +\left(F_{y b 1}+F_{y b 2}\right) c+\left(F_{y b 3}+F_{y b 4}\right)(c+2 a)=0 .
\end{aligned}
$$

By MATLAB/Simulink simulation, we can get curves about the ratio of turning radius $\left(R / R_{0}\right)$ and yawing rate along with the change of speed, as shown in Figs. 7 and 8 .

Keeping the front wheel angles $\delta_{1}, \delta_{2}$ constant, and making the vehicle speed up continuously and evenly (the longitudinal acceleration is less than $0.25 \mathrm{~m} / \mathrm{s}^{2}$ ), until the vehicle lateral acceleration up to $6.5 \mathrm{~m} / \mathrm{s}^{2}$. Measuring speed $(u)$ and yaw rate $(\omega)$ continuously, and according to formulas $R=u / \omega$ and $a_{y}=u \omega$, we can get corresponding values of $R$ and $a_{y}$. Then we get the curve of $R / R_{0}-a_{y}$ with different lateral acceleration, shown in Fig. 9. It shows that under the condition of the steady-state, with speeding up slowly, the electric vehicle's turning radius become bigger and bigger, and the turning characteristic is understeer .

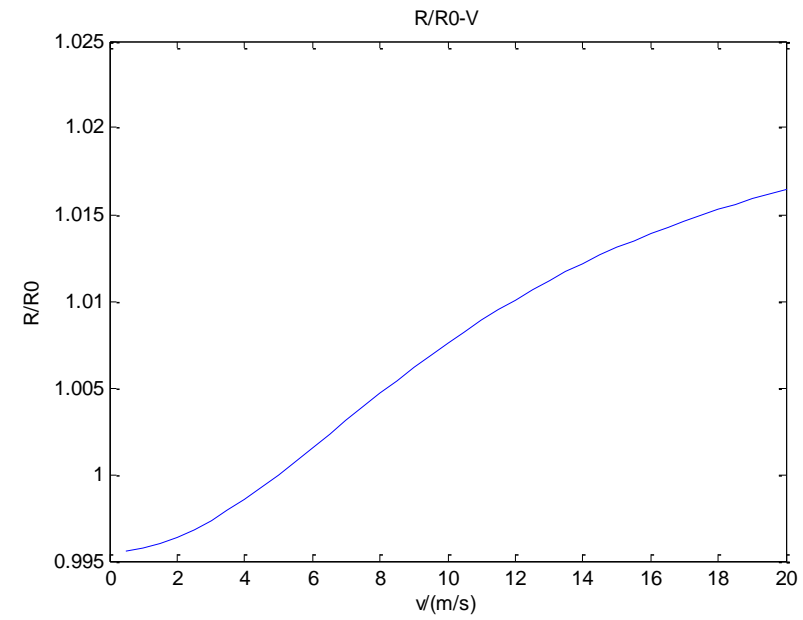

Fig. $7 R / R_{0^{-}} V$ curve of steady-state responses of the electric vehicle

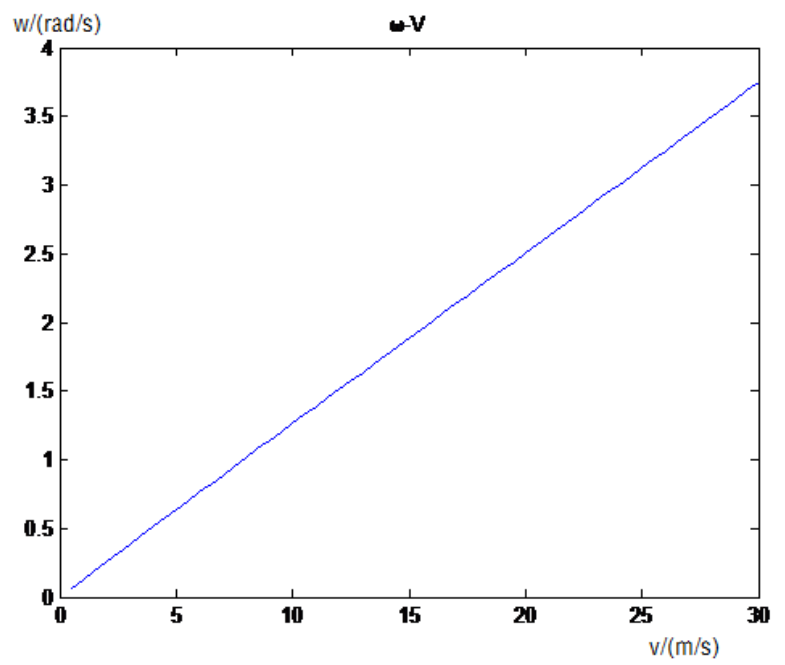

Fig. $8 \omega$ - $V$ curve of steady-state responses of the electric vehicle

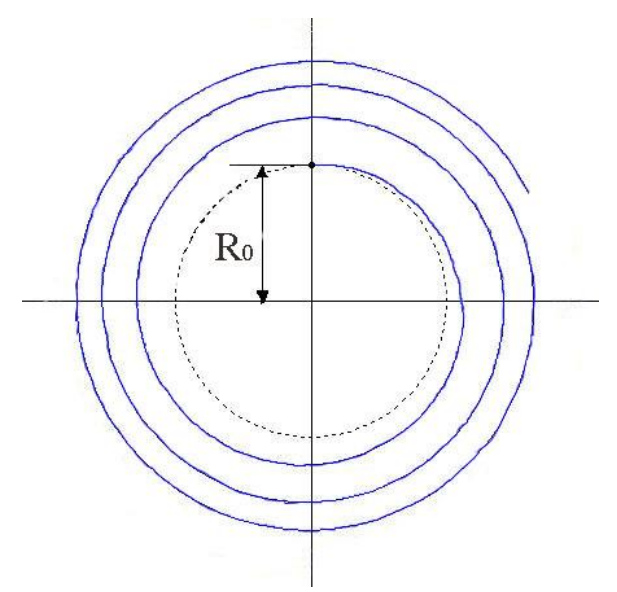

Fig. 9 Traveling track under continuous accelerated driving 
with fixed front wheel angle

3.3. The influence of different speed for steering characteristics of electric vehicle

When the vehicle is driving with a slowly speed, giving a front wheel angle, the vehicle's turning should be sensitive. When the vehicle is driving with a high speed, we gave a front wheel angle, which makes vehicle changing lanes. Carrying on front-wheel-angle-step input simulation test with speed of $10 \mathrm{~m} / \mathrm{s}, 15 \mathrm{~m} / \mathrm{s}, 20 \mathrm{~m} / \mathrm{s}$ respectively, then we can get responds curves of yaw rate and side slip angle, as shown in Figs. 10 and 11.

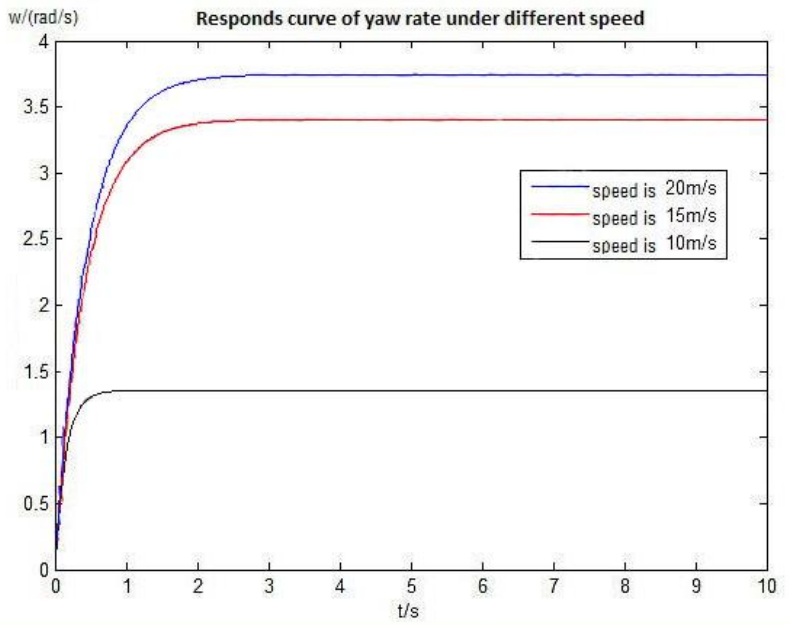

Fig. 10 Responds curve of yaw rate under different speed

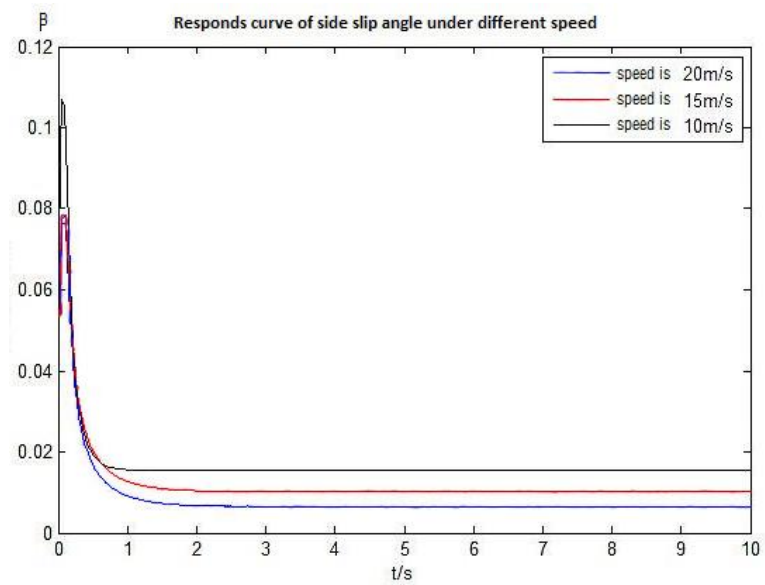

Fig. 11 Responds curve of side slip angle under different speed

According to Fig. 10, we know that with the increase of the speed of the vehicle, the stability value of yaw rate is increased. When the vehicle speed up, the reason giving a specific front wheel angle is to change lanes, then we hope the vehicle is stable. In the case of the same front wheel angle, the higher speed the more sensitive of turning.

From side slip angle curve (Fig. 11), we know that with the increase of the speed of the vehicle, the overshoot of side-slip angle is increased, reaction time was shortened, and the steady-state value decreased. According to our normal driving experience, speed reduced when the vehicle is turning to decrease the side slip angle, so that the vehicle body vertical direction is the same as the vehicle forward direction. Therefore, the tested electric vehicle has good stability.

3.4. The influence of the center of gravity to steering characteristics

It is an important characteristics that the changes in location of the center of gravity, and then we analyze the influence of different mass center position to the electric vehicle handling stability. Before the change of the center of gravity, according to the load between front axle and rare axle, we can get the location of the center of mass, that is $l_{f}=1.154 \mathrm{~m}$ and $l_{r}=1.394 \mathrm{~m}$, and the vehicle mass center is located before the center of the vehicle size.

To study the effect of the center of gravity, fixed speed, we can get response curves of constant location, center of mass forward $0.1 \mathrm{~m}$ and center of mass back $0.1 \mathrm{~m}$ by changing the longitudinal position of the battery pack, shown in Figs. 12 and 13.

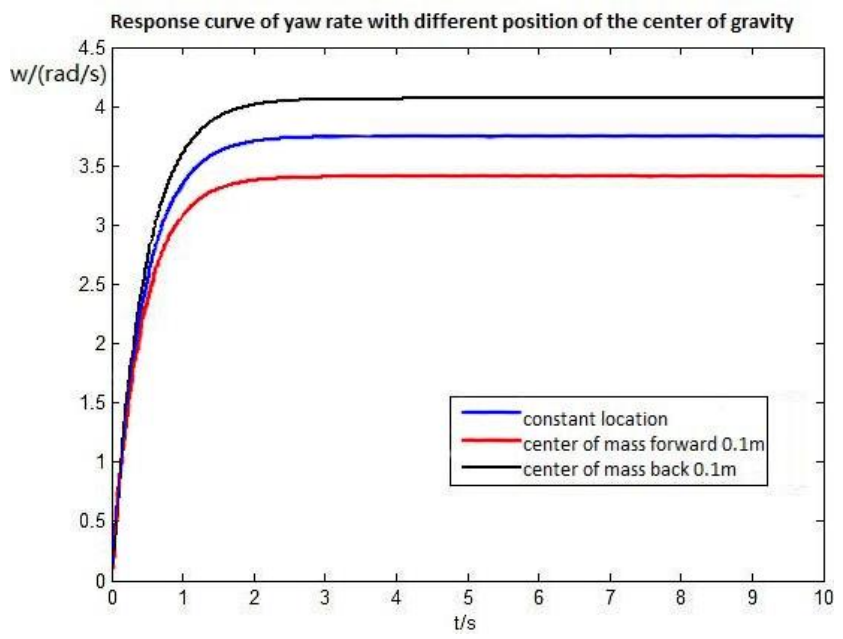

Fig. 12 Center of mass in the front-response curve of yaw rate with different position of the center of gravity

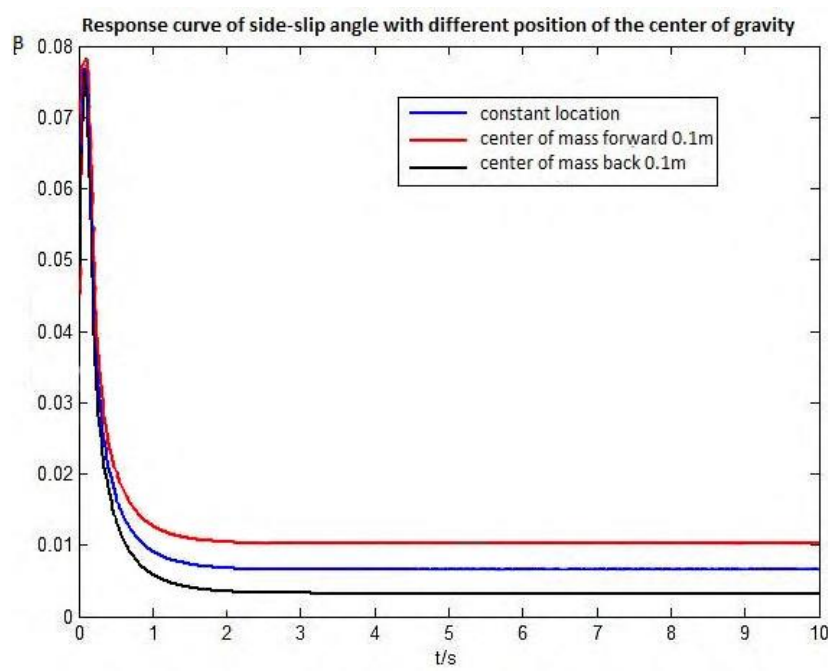

Fig. 13 Center of mass in the front-response curve of side-slip angle with different position of the center of gravity

By contrasting and analyzing three groups of curve about yaw rate, we can get conclusions: when the center of mass is located before the center of vehicle size, changing the position of the battery pack, as the center of mass going 
backward, the stable time of yaw rate is shorten, but the stable value is increased. The result of mass center forward is opposite.

To side-slip angle, we can get conclusions: as the center of mass going backward, the overshoot of side-slip angle is decreased, and the stable time is shorten. The result of mass center forward is opposite.

Changing the position of battery pack to make the center of mass is located in the center of the vehicle size. So $l_{f}=1.394 \mathrm{~m}$ and $l_{r}=1.154 \mathrm{~m}$, then we can get response curves of constant location, center of mass forward $0.1 \mathrm{~m}$ and center of mass back $0.1 \mathrm{~m}$ by changing the longitudinal position of the battery pack, shown in Figs. 14 and 15.

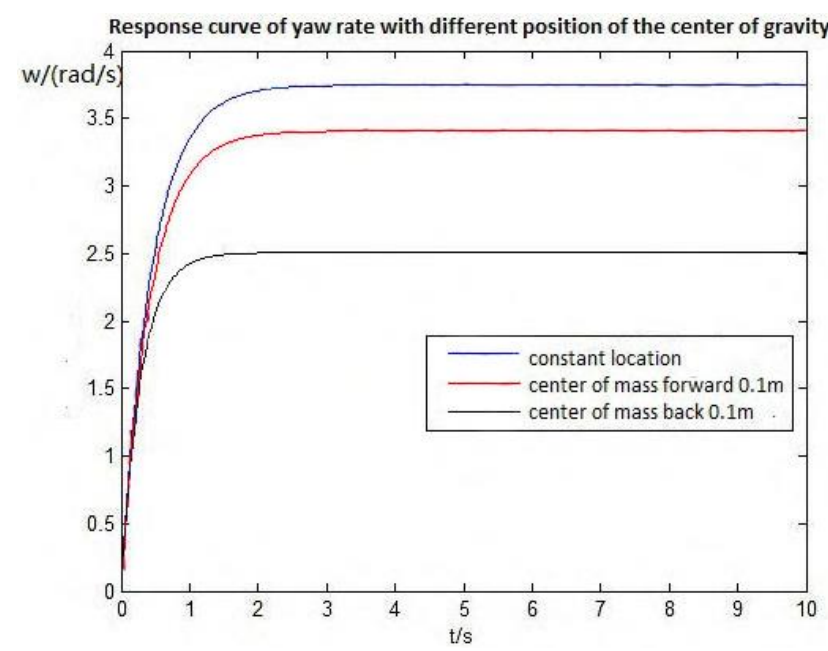

Fig. 14 Center of mass in the back-Response curve of yaw rate with different position of the center of gravity

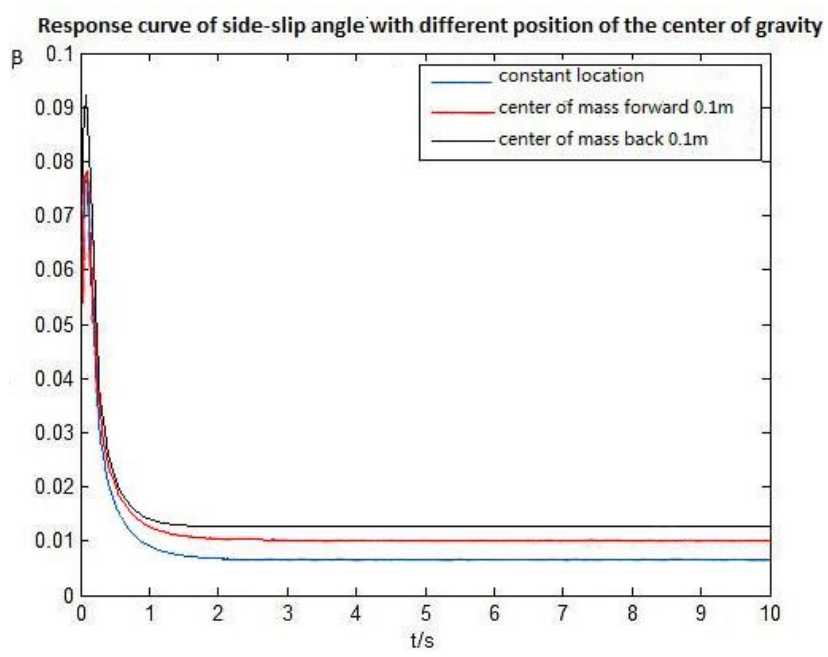

Fig. 15 Center of mass in the back-response curve of sideslip angle with different position of the center of gravity

According to Figs. 14 and 15, we can know when the center of mass is located after the center of vehicle size, changing the position of the battery pack, as the center of mass go backward, the response time of yaw rate is extended, but the time reaches a stable is shorten, and the steady-state value is decreased. The overshoot of side-slip angle is decreased, the response time extend, and the steady-state value is decreased.

Usually, when the mass of center go backward, rear wheels' vertical load and cornering stiffness are increasing, and side-slip angle is decreasing. But front wheels' side-slip angle is increasing, so the different value of slip angle between front and rear wheel is increasing, and the tendency of understeer is increasing. If the front wheel angle is constant, the corresponding yaw rate and side-slip angle are decreasing [10].

\section{Conclusions}

This paper studied turning characteristic simulation model of the electric vehicle, conducting simulations with side-slip angle and yaw rate, and simulation with different location in center of mass, then input the result of simulation to the workspace to map the response curves. By analyzing the simulation results of the system model, we can see that there is certain understeer when the electric vehicle is turning. Changing the position of the battery pack, to make the vehicle's mass center is located back in the center of vehicle size is more stable than front in the center of vehicle size.

\section{References}

1. Liang, FU Study of the characteristics of vehicles' steering mechanism, Chongqing: Chongqing University of Technology.

2. Wei, HU 2012. The effect of Four-wheel alignment parameters on vehicle handling and stability. Anhui: Hefei University of Technology.

3. Durstine, J.W. 1973. The Truck Steering system from hand wheel to road wheel, SAE Technical Paper.

4. Xiangdong, MOU; Xinpeng, TANG 2002. A preliminary study on roll steering characteristics of compliance suspension of vehicle, Journal of Highway and Transportation Research and Development 19(3): 144-146. http://dx.doi.org/10.3969/j.issn.1002-0268.2002.03.041

5. Dongming, WANG 2004. Steering behavior and control technology of Four-wheel steering automobile, Modern Machinery 6: 73-75.

http://dx.doi.org/10.3969/j.issn.1002-6886.2003.06.033

6. Jianghua, FU; Kainian, CHAO; Jianming, DING 2007. The influence of mass transfer on steering characteristics of four-wheel steering vehicle, Xihua University Natural Science 26(4): 17-19. http://dx.doi.org/10.3969/j.issn.1673-159X.2007.04.00 7.

7. Zhisheng, YU 2009. Elementary vehicle dynamics, Beijing: China Machine Press.

8. Shengqin, LI; Li, ZHAO 2014. Study of vehicle steering characteristics based on Simulink, Small Internal Combustion Engine and Motorcycle 4: 44-48. http://dx.doi.org/10.3969/j.issn.1671-0630.2014.04.010

9. Shengwei, WANG 2010. Discussion of vehicle steering characteristics, Silicon Valley 15: 20-30. http://dx.doi.org/10.3969/j.issn.1671-7597.2010.15.008 
Yang Liu, Jianzhu Zhao, Fachao Jiang

STUDY ON THE INFLUENCE OF THE

ARRANGEMENT OF BATTERY PACK ON THE STEERING CHARACTERISTICS OF ELECTRIC VEHICLE

S u m m a r y

This paper established the three degree of freedom mathematical model, based on the two degree of freedom linear model with two wheel steering. Then the dynamics differential equation is obtained. With a step input of the front wheel, observing and analyzing the yaw rate response and the side slip angle response in the whole process based on MATLAB/Simulink. Finally, by changing the position of the battery pack to transform the location of the gravity center of the whole vehicle, analyzing the impact on the electric vehicle's steering characteristic while the location of battery pack changed.

Keywords: electric vehicle, dynamic model, simulation, battery pack.

Received November 27, 2015 Accepted November 25, 2016 